\title{
ARE BUILDING CODES EFFECTIVE AT SAVING ENERGY? EVIDENCE FROM RESIDENTIAL BILLING DATA IN FLORIDA
}

\author{
Grant D. Jacobsen \\ Matthew J. Kotchen \\ Working Paper 16194 \\ http://www.nber.org/papers/w16194
NATIONAL BUREAU OF ECONOMIC RESEARCH
1050 Massachusetts Avenue
Cambridge, MA 02138 \\ July 2010
}

We are grateful to Lucas Davis, Meredith Fowlie, Marvin Horowitz, Randy Walsh, Frank Wolak, and seminar participants at Berkeley, Harvard, NBER, and RFF for helpful comments and discussions. The views expressed herein are those of the authors and do not necessarily reflect the views of the National Bureau of Economic Research.

NBER working papers are circulated for discussion and comment purposes. They have not been peerreviewed or been subject to the review by the NBER Board of Directors that accompanies official NBER publications.

(C) 2010 by Grant D. Jacobsen and Matthew J. Kotchen. All rights reserved. Short sections of text, not to exceed two paragraphs, may be quoted without explicit permission provided that full credit, including () notice, is given to the source. 
Are Building Codes Effective at Saving Energy? Evidence from Residential Billing Data in Florida

Grant D. Jacobsen and Matthew J. Kotchen

NBER Working Paper No. 16194

July 2010

JEL No. Q48,Q51

\begin{abstract}
$\underline{\text { ABSTRACT }}$
In response to the 1973 oil embargo, many states began passing building energy codes in order to promote energy efficiency. While the vast majority of states have energy codes in place, policymakers are now attempting to legislate energy codes at the federal level to help address more recent concerns about energy efficiency and climate change. Nevertheless, surprisingly little is known about whether energy codes are an effective way to reduce energy consumption in practice. This paper provides the first evaluation of an energy-code change that uses residential billing data on both electricity and natural gas, combined with data on observable characteristics of each residence. The study takes place in Gainesville, Florida, and the empirical strategy is based on comparisons between residences constructed just before and just after Florida increased the stringency of its energy code in 2002 . We find that the increased stringency of the energy code is associated with a 4-percent decrease in electricity consumption and a 6-percent decrease in natural-gas consumption. The pattern of savings is consistent with reduced consumption of electricity for air-conditioning and reduced consumption of natural gas for heating. We also estimate economic costs and benefits and find that the private payback period for the average residence is 6.4 years. The social payback period, which accounts for the avoided costs of air-pollution emissions, ranges between 3.5 and 5.3 years.
\end{abstract}

\author{
Grant D. Jacobsen \\ Department of Planning, Public Policy, \\ and Management \\ 1209 University of Oregon \\ 119 Hendricks Hall \\ Eugene, OR 97403 \\ gdjaco@uoregon.edu \\ Matthew J. Kotchen \\ School of Forestry \& Environmental Studies \\ Yale University \\ 195 Prospect Street \\ New Haven, CT 06511 \\ and NBER \\ matthew.kotchen@yale.edu
}




\section{Introduction}

Improving energy efficiency is an increasingly important component of energy policy in the United States. In addition to longstanding concerns about resource scarcity and national security, recognition of climate change and the need to reduce greenhouse gas emissions has further elevated the importance of energy efficiency. Much attention is focused on improving efficiency in the built environment, as buildings account for roughly 72 percent of the electricity consumption, 39 percent of all energy use, and 38 percent of the carbon dioxide emissions in the United States (USGBC 2009). Building energy codes (hereafter “energy codes”) are the primary policy instrument for influencing the energy efficiency of newly constructed buildings. The vast majority of states have state-wide energy codes for both commercial and residential buildings (U.S. DOE 2009), and increasing the stringency of energy codes has been a priority of the U.S. Department of Energy for decades.

Recently, the policy relevance of energy codes has increased markedly with their inclusion in pending legislation for a national policy to address climate change. The Waxman-Markey climate bill (H.R. 2454) that recently passed in the U.S. House of Representatives requires that all states enact residential building codes by 2014 that are 30 percent more stringent than the 2006 International Energy Conservation Code Standard, and the target increases to 50 percent more efficient in 2017. Thereafter the bill calls for a 5 percent increase every 3 years until 2029. Though less explicit, the Boxer-Kerry bill in the Senate (S. 1733) also includes provisions for increased stringency of energy codes. It states that the U.S. Department of Energy shall promulgate regulations establishing building code energy efficiency targets beginning not later than January 1, 2014. Moreover, in terms of energy codes themselves, the bill states that such regulations shall be sufficient to meet the national building code energy efficiency targets in the most cost-effective manner, and may include provisions for state adoption of a national building code standard.

Despite proposals for such sweeping changes to residential energy codes, surprisingly little is known about how energy codes affect residential energy consumption in practice. Evaluations are typically based on engineering simulations that compare energy usage of a base- 
line pre-code-change residence to that of a baseline post-code-change residence. ${ }^{1}$ While this approach is useful in many respects, particularly for making ex ante predictions, it has a number of potential limitations. First, changes in energy codes may not affect building infrastructure if the codes are not effectively enforced or if the codes are not stringent enough to be binding. Evidence at the state level suggests, for example, that energy codes for the thermal resistance of household insulation had no significant influence on actual levels of insulation (Jaffe and Stavins 1995). More generally, Jaffe and Stavins (1995) conclude that their analysis "does not suggest that building codes made any significant difference to observed building practices in the decade 1979-1988” (p. S61). Second, even if energy codes are effective at changing infrastructure, engineering simulations take no account of potential behavioral responses. For instance, improvements in energy efficiency decrease the effective price of energy-related services, such as airconditioning, which may stimulate demand and produce a so-called "rebound effect." ${ }^{2}$ Third, if the assumptions that engineering models are based on are not accurate, then realized energy savings will be different than predicted energy savings. Metcalf and Hassett (1999), for example, find that the realized returns of attic insulation differ significantly from those predicted by an engineering model. Specifically, they find that that while a simulation model predicts an annual savings of 50 percent, the realized returns are substantially lower at only 9 percent.

It is interesting to note that the concerns described here parallel those discussed in the early 1990s about energy efficiency in "The Great Negawatts Debate" between Amory Lovins (1994) and Paul Joskow (1994; see also Joskow and Marron 1993). Highlighting the importance of going beyond engineering approaches, Joskow (1994) writes, "Technical potential studies of the kind that Lovins relies on may be useful to this process [promoting efficiency], but standing

\footnotetext{
${ }^{1}$ DOE-2 and EnergyGauge are two common software programs used to conduct simulation models on the effect of energy-code changes on energy use. Examples of two government-commissioned evaluations of residential energycode changes are Fairey and Sonne (2007) for the Florida Department of Community Affairs and Lucas (2007) for the U.S. Department of Energy. The former studies real policy changes in Florida, and the latter predicts what might happen with policy changes in the gulf coast region. Both conclude that residential energy-code changes can result in substantial energy savings. Links to a number of other studies can be found through the U.S. Department of Energy's Building Energy Codes Program online at www.energycodes.gov/implement/tech_assist_reports.stm.

${ }^{2}$ Greening et al. (2000) survey the literature on rebound effects and find implied residential elasticities of 0.1 to 0.3 for space heating, 0 to 0.5 for space cooling, 0.05 to 0.12 for water heating, and 0.1 to 0.4 for lighting.
} 
alone they are not very meaningful because they don't even purport to measure actual behavior and performance of real institutions...” (p. 50).

In this paper, we employ a different methodology to evaluate whether energy codes affect residential energy consumption. Rather than conduct simulations, we take advantage of utility billing data to directly compare actual energy consumption of households built under different energy-code regimes. Because the approach is based on actual changes in both the building code and energy consumption, the approach accounts for changes in construction practices, or lack thereof, and for potential behavioral responses. Such ex post analyses based on field data are needed to more fully evaluate the effects of energy codes. The paper makes several contributions by providing (1) the first study that uses residential billing data to evaluate the effect of an increase in the stringency of an energy code on both electricity and natural-gas consumption, (2) evidence that energy codes can in fact reduce energy consumption with magnitudes relatively close to simulation estimates, (3) a cost-benefit analysis to derive both private- and socialpayback periods, and (4) a template for how similar studies can be carried out in other areas.

The analysis is based on a change in Florida's state-wide energy code that came into effect in 2002. We obtained residential billing data on electricity and natural gas in the city of Gainesville that are combined with appraiser data for a set of observable characteristics for each residence. Indeed, a unique feature of our data, which is central to the empirical strategy, is that we have monthly billing data from the utility company combined with characteristics of each residence. Our evaluation of the impact on energy consumption is based on comparisons between residences constructed within three years before and three years after the energy-code change was implemented. Using monthly utility bills for all residences in the years after the code change, we employ two empirical strategies to evaluate how energy-code changes affect both electricity and natural-gas consumption. The first is an analysis of consumption levels after controlling for differences in observable characteristics. The second is difference-in-differences estimates of the responsiveness of energy consumption to variability in weather. The first approach produces our main results: the energy code appears to have caused a 4-percent decrease in annual electricity consumption and a 6-percent decrease in annual natural-gas consumption. Moreover, 
the differences in the energy savings by month and weather variability are consistent with reduced consumption of electricity for air-conditioning and reduced consumption of natural gas for heating, which are the two main end-uses that are targeted by energy codes. Finally, we consider the costs and benefits of the energy-code change on a per residence basis. The costs consist of increased compliance costs, while the benefits consist of lower expenditures on utility bills and avoided social costs of air-pollution emissions. We find that, under the best-case scenario, the private payback period is 6.4 years, and the social payback period ranges between 3.5 and 5.3 years, depending on whether avoided damages from carbon dioxide are included.

In terms of related studies that explicitly evaluate the effect of energy codes, we are aware of only one that uses a research design similar to our first strategy. Horowitz and Haeri (1990) conduct a cross-sectional analysis of annual electricity consumption for electrically heated residences built before/after conservation standards for these homes were first implemented in Tacoma, Washington. They find with a relatively small sample size that the standards are consistent with a 13.7 percent decrease in electricity consumption. In contrast to their study, however, we consider the effects of strengthening an existing code rather than implementing a new code, the former being the more policy-relevant question at a time when attention is focused primarily on strengthening existing codes. We also consider both electricity and natural-gas consumption for all residences and not just electricity consumption for residences with electric heat. Finally, unlike Horowitz and Haeri (1990), we have monthly observations for repeated years, and this proves central to our second empirical strategy that allows us to control for residence fixed effects.

Two recent working papers also address questions about the effectiveness of building codes, though both employ methodologies that differ from the ones used here. Arroonruengsawat et al. (2009) use per capita electricity consumption in 48 U.S. states to investigate the impact of residential building codes, and they find decreases in per capita consumption between 3 and 5 percent in states that have adapted codes and experienced significant amounts of new construction. Costa and Kahn (2010) use household-level data in Sacramento, California and find that, after controlling for the price of electricity, decreases in consumption after 1983-vintage resi- 
dences appear consistent with implementation of California’s residential building codes. While both of these studies contribute much needed evidence on the effectiveness of energy codes, our study makes a different contribution because we use micro-data on both electricity and natural gas, make explicit comparisons to engineering simulations, and calculate private and social payback periods.

The remainder of the paper is organized as follows: Section 2 describes the empirical setting of our study along with the methods of data collection. Section 3 reports the results of the main empirical analysis. Section 4 provides estimates of the costs, benefits, and payback periods. Section 5 discusses the results and compares them to those of an engineering simulation model. Section 6 concludes with a brief summary and remarks about the generalizability of our results.

\section{Empirical Setting and Data Collection}

Residential construction in Florida has been regulated under a state-wide energy code since 1978. Like the energy codes in most states, Florida's residential code sets a minimum energy efficiency standard for space heating, space cooling, and water heating. Florida's code is a performance-based code, which means that the overall efficiency of a new home is considered rather than its specific component parts. In order to comply with the code, which is required to obtain a building permit, newly constructed residences are compared with a baseline home that establishes an overall energy standard, sometimes referred to as an “energy budget.” While certain components of the newly constructed home can be less efficient than the baseline home, the new home's overall efficiency rating must meet or exceed that of the baseline home-that is, the residence must stay within its energy budget. Characteristics of the baseline home determine the stringency of the energy code, and these characteristics have changed over time in Florida.

This paper considers the effect of changes adopted by the Florida Building Commission for the 2001 Building Code that were first implemented on March 1, 2002. At the time, three major changes were made to the energy code. First, for the central and south Florida climate regions, the baseline heating system was changed from electric strip resistance with a Heating Season Performance Factor (HSPF) of 3.4 to an electric heat pump with an HSPF of 6.8. The more 
stringent HSPF was already in place in the northern climate region. Second, the assumed airdistribution system of the baseline home was changed from "leak free" to "leaky." This effectively relaxed one aspect of the code because homes determined to be leak free could earn a substantial credit for having an improved air-duct system. ${ }^{3}$ Third, the Solar Heat Gain Coefficient (SHGC), which is the amount of solar heat the passes through a window compared to how much strikes it on the outside, was reduced from 0.61 to 0.4 . This change was the most substantial and expected to have a large impact in all three of Florida’s climate regions.

These three major changes to the energy code were designed to bring the 2001 Florida Building Code into alignment with the International Energy Conservation Code (IECC), and together they led to a substantial increase in the stringency of Florida's regulation. ${ }^{4}$ According to EnergyGauge (2002), which is the authorized code-compliance software for Florida, the estimated increase in stringency was 4, 15, and 10 percent for the northern, central, and southern regions, respectively. These predicted percentage changes in stringency, however, apply only to energy used for space heating, space cooling, and water heating.

We focus in this paper on how changes in the residential energy code translate into changes in actual energy consumption. In particular, we focus on the changes to Florida's energy code that applied in the northern climate region. We obtained residential utility data for households in the city of Gainesville, which is located in the northern part of the state. The data were downloaded from Gainesville-Green.com, which is a website designed to encourage energy conservation through provision of publicly-available information on household energy consumption. ${ }^{5}$ Included in the dataset are monthly billing records for electricity and natural-gas consumption for residential households. Residences included in the Gainesville-Green dataset were se-

\footnotetext{
3 "Leak free" in the Florida energy code is defined as air leakage less than 5 percent of the rated air handler flow at a pressure of 25 Pascal (0.1 inches water gauge). The energy credit for qualifying as leak free is substantial, ranging between 13 and 15 percent of heating and cooling energy.

${ }^{4}$ Smaller changes were also made to the code that might impact compliance under certain circumstances: 1) energy credits for certain white roofing products, 2) a greater penalty for air-handler units located in attics, 3) updated multipliers for attic insulation, 4) inclusion of multipliers for Interior Radiation Control Coatings (IRCC), and 5) credits for factory-sealed air handlers. Further details about all changes in Florida's 2001 energy code are available online, along with the official compliance software (EnergyGauge 2002).

${ }^{5}$ Gainesville-Green.com is a cooperative effort among The City of Gainesville, Gainesville Regional Utilities, the University of Florida's Institute for Food and Agricultural Sciences, the International Carbon Bank and Exchange, and Acceleration.net. The first version of Gainesville Green appeared online in 2008.
} 
lected based on the criteria of having 12 months of electric service in 2006 and the meter matching a single building on its parcel. While the complete set of monthly billing data spans 2000 through 2006, we use only data from 2004 through 2006, the period that includes residences built before and after the energy-code change. ${ }^{6}$ Also included in the data is detailed information on housing characteristics, including information on zip code, square footage, number of bathrooms, number of bedrooms, number of stories, air-conditioning, roof type, and effective year built. ${ }^{7}$

The housing characteristic of primary interest is effective year built (EYB) because it enables us to determine when a residence was constructed and, in particular, whether it was subject to the energy code regime before or after the 2001 changes came into effect. EYB typically indicates the year when construction was completed-i.e., year of the final inspection—but it can also indicate the year when the last major remodeling occurred. In order to focus on residences for which EYB indicates the year when initial construction was completed—which, as explained below, we use to determine the corresponding energy-code regime-we drop any residence in the data with a utility bill on record prior to its EYB, as this suggests EYB indicates a remodeling year.

Using EYB to categorize the remaining residences as being constructed pre- or post-code change, we must also take account of the fact that Florida's energy code is enforced when building permits are issued and not when final inspections take place. Evidence suggests that the average time between initial permitting and final inspection is about six months for residential construction (Bashford et al. 2005; Burk 2008). We thus categorize residences as pre- or post-code change, which took effect in March 2002, as follows: EYB of 2001 or earlier designates a residence as pre-code change; EYB of 2003 or later designates a residence as post-code change; and EYB of 2002 designates a residence as indeterminate because the corresponding building-code

\footnotetext{
${ }^{6}$ Though not reported here, we also conduct analyses that incorporate the data for years 2000 through 2003. But, as will become clear later, the earlier data adds nothing to identification of the energy-code effects, because post-codechange residences were not constructed yet. Nevertheless, as might be expected, the results are robust to models that include the additional data.

${ }^{7}$ Not included in the dataset are variables from which to identify changes in tenancy at each residence and an indicator of the residence's billing cycle, which determines the day in each month when a residence's electric meter is read. The fact that these variables are not included in the dataset does not, however, create problems for our empirical strategy.
} 
regime is unclear. We thus drop from the analysis, unless otherwise indicated, all residences with an EYB of 2002. ${ }^{8}$

We also exclude from the analysis all residences with an EYB of 1998 or earlier. These observations are excluded for two reasons. First, Florida's energy code also changed in November 1997. This means that all residences with an EYB up to and including 1997, and some of the residences with an EYB of 1998 (because of the lag between permitting and final inspection), were subject to a different energy-code regime than those with an EYB of 1999 through 2001. ${ }^{9}$ Second, and more importantly, our empirical strategy is based on a comparison of residences built before and after the energy-code change. The best comparison is based on residences built just before and just after the code change, as this minimizes the possibility that some unobservable time trend in housing construction will bias the analysis. The basic idea is that residences constructed at more similar points in time are likely to be more similar in terms of both their observed and unobservable characteristics.

A few more steps are necessary to clean and prepare the data. To address partial occupation of new construction, we exclude the first 12 months of utility billing data for new residences. The pattern of partial occupation for newly constructed homes is clearly seen in the data. For example, mean electricity use is 45 percent less in the first month than in the thirteenth month. While the pattern becomes less pronounced in subsequent months, until it levels off around month eight, we conservatively drop the first 12 months. One implication is the exclusion of all 47 residences with an EYB of 2006, and thus the newest residences in the data have an

\footnotetext{
${ }^{8}$ While it is possible that some residences with an EYB of 2003 were also constructed under the pre-code regime, categorizing them as we do might only be a concern because of the potential for attenuation bias.

${ }^{9}$ Including residences with and EYB of 1998 or earlier would therefore require consideration of more than one change to the state's energy code. While in principle our empirical strategy would enable us to study Florida's 1997 code change, it is complicated by the fact that the change actually made the overall code less stringent. Moreover, it appears that Florida's building code was not well-enforced during the 1990s. The Alachua County website reports that "During the early 1990's a series of natural disasters, together with the increasing complexity of building construction regulation in vastly changed markets precipitated the comprehensive review of the state building code system. The study revealed that building code adoption and enforcement was inconsistent throughout the state and those local codes thought to be the strongest proved inadequate when tested by major hurricane events. The consequences were devastation to lives and economies and a statewide property insurance crisis. The response was reform of the state building construction system which placed emphasis on uniformity and accountability (Alachua County, 2009)." For this reason, and because we are interested primarily in the effect increasing the stringency of energy codes (which is not likely to be symmetric with relaxing energy codes), this paper focuses on the 2001 code change alone.
} 
EYB of 2005. Though relatively minor, we also drop residences recorded as having less than one story, monthly electricity observations with a negative or zero quantity, and monthly natural-gas observations with a negative quantity. These drops account for 3,130 observations, 256 observations, and 375 observations, respectively, or 5.8 percent of the complete dataset, which includes a total of 64,471 observations.

Finally, we collect weather data from the National Climatic Data Center for the Gainesville area and merge it with the monthly utility data. We download daily weather data from a single weather station located at the Gainesville regional airport. ${ }^{10}$ Two weather variables are of interest for our analysis: average heating degree days (AHDD) and average cooling degree days (ACDD). Using standard practice, the reference point for calculating degree days is $65^{\circ}$ Fahrenheit $(\mathrm{F})$. When average daily temperature falls below $65^{\circ} \mathrm{F}$, the difference is the number of heating degrees in a day. When average daily temperature exceeds $65^{\circ} \mathrm{F}$, the difference is the number of cooling degrees in a day.

We then merge the daily weather data with the monthly utility data. Because we do not know the billing cycle of each residence (i.e., the start and end date of each bill), we cannot match the daily weather data to the exact days of each utility bill. Instead, we calculate averages for the weather data from the $15^{\text {th }}$ to the $15^{\text {th }}$ of adjacent months (or the $14^{\text {th }}$ in the case of February) and merge these averages with the monthly billing data that matches the later 15 days over which the average was taken. For example, all utility bills for the month of June are matched with weather data averaged between May $15^{\text {th }}$ and June $15^{\text {th }}$ of the same year. Assuming that the billing cycles are uniformly distributed, this procedure maximizes the number of weather-data days that correspond with the days of each utility bill. It is a simple matter to verify that the number of correctly corresponding days ranges from a minimum of 50 percent to a maximum of 100 percent.

\footnotetext{
${ }^{10}$ We use station number 083362 in the National Weather Service's Cooperative Station Network. This station is the closest one to our study area that was running continuously over the period for which we have utility data. The data can be downloaded at http://www.ncdc.noaa.gov/oa/climate/climateinventories.html.
} 
The complete dataset that we use for the analysis includes 2,239 residences among the 64,471 monthly observations. Table 1 reports basic summary statistics. Mean electricity consumption is 1,146 kilowatt-hours (kWh) per month. Mean natural-gas consumption is approximately 24 therms per month. The average residence is 2,072 square feet in size, has 2.3 bathrooms, 3.4 bedrooms, and 1.1 stories. Nearly all residences have central air-conditioning and a shingled roof. The mean of ACDD is 7.6 and the mean of AHDD is 3.2.

Among the residences, 1,293 were built before the energy-code change, and 946 were built after the energy-code change. Table 2 compares the energy consumption and residential characteristics of residences built before and after the code change. Residences built after the code change use less electricity and less natural gas. While these differences are consistent with the energy code having resulted in an energy savings, regression analysis of the type we perform in the next section is necessary to control for observable characteristics of the residences and for the fact that not all residences are observed for the same number of months (e.g., post-code change residences are more likely to be observed toward the end of the sample period). The other residential characteristics in Table 2 are quite similar between groups, with the notable exception that those built after the energy-code change are smaller by 94 square feet on average, or roughly 4.5 percent. The other housing characteristics with statistically significant differences are central air-conditioning and shingled roofs, but the magnitudes of the differences are exceedingly small.

\section{Empirical Analysis}

The change in Florida's 2001 energy code combined with the Gainesville data on residential characteristics and utility consumption provides an opportunity to examine the effect of energy codes on actual electricity and natural-gas consumption. This section describes our empirical strategy and results. We first conduct pre- and post-code-change comparisons to estimate annual and monthly differences in energy consumption between residences subject to the before and after energy-code regimes. We then conduct a difference-in-differences analysis based on weather variability that tests whether or not the effect of the code is greatest when demand for space heating and cooling are greatest. Because Florida’s energy code only regulates energy efficiency re- 
lated to space heating, space cooling, and water heating, we expect that the effect of the code, if it exists, will be greatest during months when the demand for heating and cooling makes up a relatively greater share of a household's energy demand. For electricity, we expect that the effect of the code change will be greatest in the summer months when electricity demand for airconditioning is at its peak. For natural gas, we expect that the effect of the code change will be greatest in the winter months when demand for natural-gas based heating is at its peak.

\subsection{Pre- and Post-Code-Change Comparisons}

We begin the before-and-after comparisons with linear regression models of the form

$$
Y_{i t}=\delta \text { CodeChange }_{i}+\boldsymbol{\beta} \boldsymbol{X}_{i}+v_{t}+\varepsilon_{i t},
$$

where the dependent variable $Y_{i t}$ is either monthly electricity consumption $(\mathrm{kWh})$ or monthly natural gas consumption (therms), depending on the model; $i$ indexes residences; $t$ indexes the month-year of the billing record; CodeChange $e_{i}$ is an indicator variable for whether the residence was constructed after the energy-code change; $\boldsymbol{X}_{i}$ is a vector of explanatory variables, including the natural $\log$ of the residence's square feet, indicator variables for central air-conditioning and shingled roofing, and dummy variables for the number of bathrooms, bedrooms, stories, and zip code (of which there are nine in the dataset); $v_{t}$ is a month-year specific intercept that controls for month-to-month effects common to all residences, such as weather fluctuations or changes in the price of electricity or natural gas; and $\varepsilon_{i t}$ is a normally distributed error term. The estimate of $\delta$ is of primary interest, as it captures the average difference in either electricity or natural-gas consumption between households built before and after the energy-code change. An estimate of $\delta$ less than zero would, for example, be consistent with the energy-code change causing a decrease in energy consumption.

We estimate the parameters of specification (1) using ordinary-least squares (OLS). To account for potential serial correlation of the error terms, we report standard errors that are clus- 
tered at the residence level. We also test for robustness with alternative specifications. In a more flexible specification, we allow the month-year effects to differ by each zip code, which we accomplish by interacting $v_{t}$ with each of the zip code dummies. We also estimate log-linear specifications of the model — and all others throughout the paper-but we do not report the results for several reasons other than brevity. First, the qualitative results are very similar to the estimates that we do report based on levels. Second, the log-linear specifications tend not to fit the data as well in many cases. Finally, the estimate of $\delta$ in a log-linear specification is not precisely an overall annual average because of the nonlinearity and the fact that consumption differs substantially between months of the year. ${ }^{11}$

Table 3 reports the estimates of specification (1) for electricity and natural gas (columns 1 and 3), along with the additional specifications that allow the time effects to differ by each zip code (columns 2 and 4). Focusing first on the electricity results, we find that the models fit the data well, explaining roughly 50 percent of the variation in residential electricity consumption. The coefficient estimates are very similar between the two specifications, one with a single set of month-year dummies and one with zip-code-by-month-year dummies. Based on the two models, we find, after controlling for observables, that households built after the energy-code change consume approximately $48 \mathrm{kWh} /$ month less than households built before the energy-code change, and the result is statistically significant at the 95-percent level. In terms of a percentage difference, the estimates suggest that the energy-code changes result in a 4-percent decrease in residential electricity consumption. Not surprisingly, we also find that larger residences consume more electricity, and the result is statistically significant. In particular, the coefficient estimates are interpreted such that, for example, a 10-percent increase in the square footage of a residence is associated with an increase of $96 \mathrm{kWh}$, or an increase of 8.3 percent, in monthly electricity consumption.

The qualitative pattern of results is very similar for natural gas. The models fit the data reasonably well, and the coefficient estimates are very stable between specifications. The coeffi-

\footnotetext{
${ }^{11}$ The results of alternative specifications are available upon request.
} 
cient estimates on the effect of the energy-code change are again negative and statistically significant at the 95-precent level. We find that residences constructed after the code change consume approximately 1.5 therms/month less, which translates into a 6.4-percent reduction in the consumption of natural gas. Larger residences also consume more natural gas, whereby a 10percent increase in square footage is associated with an increase of 2.9 therms/month, or a 1.2percent increase in natural gas consumption. We also find some evidence that central airconditioning and a shingled roof affect natural gas consumption, but the statistical significance of the results is weaker and perhaps questionable, as identification comes from exceedingly few observations.

While the models presented in Table 3 provide an estimate of the code-change effects averaged across all months, the effects may differ in important ways among months of the year. Weather varies throughout the year and substantially affects demand for cooling and heating, which are known to have a large influence on demand for electricity and natural gas, respectively. We thus estimate expanded versions of specification (1) for electricity and natural gas as follows:

$$
Y_{i t}=\delta \text { CodeChange }_{i} \times \text { Month }_{t}+\beta \boldsymbol{X}_{i}+v_{t}+\varepsilon_{i t},
$$

where $\boldsymbol{M o n t h}_{t}$ is a vector of dummy variables for each of the 12 months in the calendar year. The only difference is that we now estimate the code-change effect separately for each month of the year. We estimate models based on specification (2) in the same way: OLS, standard errors clustered at the residence level, uniform time effects, and zip-code specific time effects.

For simplicity and brevity, however, we summarize the main findings with two figures. We take the coefficients of interest in the basic specification (2) - the $\delta$ for each month of the year-and report it as the percentage change from average consumption for that particular month. Figure 1 illustrates the electricity results for the average monthly effects along with the 95-percent confidence intervals. The overall pattern is clear: compared to residences built before 
the energy-code change, those built after consume roughly the same electricity during the colder months, but substantially less during the warmer months. Between April and October, all of the point estimates are statistically different from zero and range between 4 and 8 percent less electricity. The obvious explanation for these results is the impact of energy codes on the efficiency of air-conditioning, which is used during the warmer months of the year. Nearly all households in Gainesville have central air-conditioning, and throughout the South Atlantic region of the United States, air-conditioning accounts for 21 percent of residential electricity consumption (EIA 2006). Holding other things constant, therefore, changes in the energy code that improve the cooling efficiency of residences would be expected to cause electricity savings during the warmer, and not necessarily the colder, months of the year. The results in Figure 1 are consistent with this expectation.

The overall pattern of results for natural gas are nearly the exact opposite, as shown in Figure 2. Compared to those built before the energy-code change, residences built after consume less during the colder months_-December, January, February—when the statistically significant point estimates range between 15 and 25 percent. But differences between the groups are not statistically significant for any of the other months during the warmer times of year. In this case, the candidate explanation is the impact of energy codes on the efficiency of heating. While the majority of residences in Florida use electric space-heating, many heat with natural gas, which comprises a substantial portion of natural-gas consumption in the winter months. It follows that, due to the energy-code change, improved energy efficiency with respect to heating would be expected to reduce natural-gas consumption during the winter months.

Our analysis thus far builds a case that changes to Florida's energy code have resulted in reduced consumption of both electricity and natural gas. The empirical strategy is based on a comparison of monthly consumption in the years after the code change between residences built within three years before and three years after the code change went into effect. Specification of the empirical models seeks to account for observable characteristics that help explain variation in energy consumption, including square footage, central air-conditioning, shingled roof and number of bedrooms, bathrooms, and stories. Moreover, the inclusion of zip-code dummies accounts 
for unobserved heterogeneity that is common among all residences within the same zip code. A potential limitation of the identification strategy, however, could be the existence of other reasons for a downward trend in residential energy consumption across years of construction that, in our analysis, is falsely attributed to the energy-code change. To partially address this potential concern, we have chosen to use only residences built within only a few years (before and after) of the energy-code change. We have also estimated models with both uniform and zip-code specific time effects. While the estimates are very similar in both cases, the latter is a useful robustness check because it accounts, to some extent, for spatial differences in time trends that might be correlated with areas of predominantly newer or older construction.

To further address the potential concern about a downward trend in energy consumption not due to the energy-code change, we estimate differences in consumption for each effective year built of the residences, while controlling for the other observable characteristics. Specifically, we estimate models of the form

$$
Y_{i t}=\boldsymbol{\theta E Y B _ { i }}+\beta \boldsymbol{X}_{i}+v_{t}+\varepsilon_{i t}
$$

where $\boldsymbol{E Y B}_{i}$ is a categorical variable for the effective year built for each residence. The vector of coefficients $\boldsymbol{\theta}$ provides estimates of the average difference in energy consumption (either electricity or natural gas) for the different years of EYB. When estimating specification (3), we include residences with an EYB of 2002 and use them as the omitted category. Recall that these residences were excluded from the previous models because the lag between building-permit issuances and final inspections made it uncertain as to whether they were subject to the before or after energy-code change regime. But in terms of exploring a potential time trend independent of the energy-code change, there is no reason to exclude these observations. 
Figures 3 and 4 illustrate the coefficients of interest for electricity and natural gas, respectively, along with 95-percent confidence intervals based on clustering at the residence level. ${ }^{12}$ Figure 3 shows no clear downward trend in electricity consumption based on the EYB from 1999 to 2005. Moreover, even though the pre-code-change estimates appear higher than the post-codechange estimates, none of the point estimates for any EYB on its own is statistically distinguishable from any other. Turning to Figure 4, there does appear to be somewhat of a downward trend in natural-gas consumption for EYBs before and after the energy-code change, but consumption increases rather than decreases for residences constructed immediately after the change. Just as we find for electricity, however, each of the point estimates shown in Figure 4 is not statistically distinguishable from any other. Based on these results—-for both electricity and natural gas—we conclude that our estimates of the energy-code change on residential energy consumption are not simply capturing an unobserved time trend. Instead, the pre- and post-code-change comparisons appear to be capturing how the more stringent energy code causes a real decrease in residential electricity and natural-gas consumption.

\subsection{Difference-in-Differences}

We now use a different empirical strategy to investigate the effect of Florida's energy-code change on residential energy consumption. In particular, we focus on how weather variabilitythe primary driver of fluctuations in residential energy consumption-may differentially affect pre and post code-change residences. Figure 5 illustrates the variability in the primary weather variables — average cooling degree days (ACDD) and average heating degree days (AHDD)—by month-year from 2004 through 2006. The basic pattern, as one might expect, is that ACDD peaks in the summer and comes close to zero in the winter months, while AHDD is zero during the summer months and peaks during the winter.

\footnotetext{
${ }^{12}$ As with all models, we also estimate specification (3) with zip-code specific time effects and a log-linear functional form. We do not report these results in the main text because they follow patterns very similar to those shown in Figures 3 and 4.
} 
As discussed previously, we combine these weather data with the billing data on electricity and natural gas. With the combined dataset we estimate models for both electricity and natural gas of the form

$$
\begin{gathered}
Y_{i t}=\boldsymbol{\beta}\left[A C D D_{t}, A H D D_{t}\right]+\delta \text { CodeChange } e_{i} \times\left[A C D D_{t}, A H D D_{t}\right] \\
+ \text { Month }_{t}+\text { Year }_{t}+\mu_{i}+\varepsilon_{i t}
\end{gathered}
$$

where the indicator variable for whether the residence was constructed after the energy-code change is interacted with each of the weather variables; $M_{0} h_{t}$ are month of the year dummies; Year $_{t}$ are year dummies; and $\mu_{i}$ is a residence-specific intercept. For purposes of comparison, we also estimate as similar specification in which the weather variables themselves, which come from a single weather station and are aggregated at the monthly level, are absorbed in monthyear dummies:

$$
Y_{i t}=\delta \text { CodeChange } e_{i}\left[A C D D_{t}, A H D D_{t}\right]+v_{t}+\varepsilon_{i t} .
$$

We estimate equations (4) and (5) with the fixed-effects estimator and cluster standard errors at the residence level. A key feature of both specifications is the residence-specific intercept (i.e., the fixed effect). This controls for any unobserved, time-invariant heterogeneity among residences. If, for example, there is an unobserved trend in average energy consumption based on EYB, as was a potential concern with our previous estimates, then the fixed effect accounts for the trend with residence-specific intercepts.

The coefficients of interest, the $\delta s$ on the interactions with ACDD and AHDD, are essentially difference-in-differences estimates of how residences before and after the energy-code change differ in their energy consumption responses to changes in weather. If the energy-code changes do in fact have an effect, we would expect the before- and after-residences to differ in their responses given that the code changes were designed to improve energy efficiency and that 
variability in weather is known to be the primary determinant of changes in residential demand for space heating and cooling, which are the primary end-uses targeted by residential energy codes. Based on both intuition and the results of the monthly before-and-after comparisons, we have strong priors about one of the coefficients in both the electricity and natural gas estimates of specifications (4) and (5). With respect to electricity, if the energy-code changes are having the intended effect, we would expect residences constructed after the code change to be less responsive to increases in ACDD. This follows because air-conditioning, which is used more intensely with more ACDD, would be more efficient in the after-code change residences. With respect to natural gas, we would expect after-code-change residences to be less responsive to increases in AHDD. This follows because natural-gas based heating, which is used more intensely with more AHDD, would be more efficient in the after-code-change residences.

The first two columns of Table 4 report the electricity estimates of specifications (4) and (5). Focusing first on the uninteracted weather variables in column (1), which apply to the before code-change residences, we find that the coefficients have the expected signs. Electricity consumption is increasing in ACDD and AHDD, and these results are all consistent with electricity being the primary energy source for cooling and heating of Florida residences. Based on the interaction with CodeChange, we find that the electricity consumption of post-code-change residences is less responsive to an increase in ACDD. In particular, the marginal effect of a one unit increase in ACDD is $2.5 \mathrm{kWh} /$ month smaller for post-code-change residences, which is a 7.8percent decrease in responsiveness to ACDD relative to the response of pre-code-change residences, which was $32.25 \mathrm{kWh} /$ month. Hence, consistent with our previous monthly results, the increase in the stringency of the energy code appears to have improved residential airconditioning efficiency. In contrast, the estimated effect with respect electricity and AHDD suggests that the after-code-change residences are less efficient with respect to electric heating. However, increased response to AHDD is less important because heating degree days are far less frequent in Florida, as shown in Figure 5. Overall, the estimates indicate that the electricity consumption of post-code-change residences is less responsive to weather-induced demand shocks than is the consumption of the pre-code change residences. The results for specification (5) are 
similar, though the magnitudes of the differences between pre- and post-code-change residences are even larger.

Turning now to the natural-gas results, we find again that the uninteracted weather variables in column (3) have the expected signs. The largest source of variability in natural-gas consumption would be due to its use in heating, which explains why consumption is increasing in AHDD and decreasing in ACDD. Based on the interactions with CodeChange, the results suggest that post-code-change residences are more efficient with respect to natural-gas consumption for heating. When an increase in AHDD causes an increase in natural gas consumption for precode-change residences, the effect is less so for post-code-change residences. In particular, the marginal effect differs by 1.3 therms/month, which is substantial at 58 percent. When a decrease in ACDD causes an increase in natural-gas consumption for pre-code-change residences, which is likely due to more demand for heating, the increase is more so for post-code-change residences. In this case, the marginal effect differs by 0.1 therms/month, which is roughly 43 percent. However, this effect is outweighed by the response to AHDD, because natural-gas consumption is much more responsive to one additional heating degree day, than to one less cooling degree day, as reflected in the magnitude of the point estimates. Overall, the estimates indicate that the natural-gas consumption of post-code-change residences is less responsive to weatherinduced demand than is the consumption of the pre-code change residences. These results are also robust to specification (5) where the coefficient estimates on the interaction terms of interest are very similar.

\section{Costs and Benefits}

We now consider the costs and benefits of the increased stringency of Florida's residential energy code. Our calculations apply directly to the study area of Gainesville, Florida in the state's northern climate region. We compare costs and benefits at the level of a single residence. The costs consist of increased compliance costs with the more stringent code, while the benefits consist of lower expenditures on utility bills and avoided social costs of air-pollution emissions. 
Estimating the increased compliance costs is not straightforward, in general, because the policy is a whole building, performance-based code that does not require specific features of new construction; instead, what matters is the overall efficiency of a residence compared to the baseline home. As explained in Section 2, the major change to the baseline home that applies in the northern climate region is the reduction in the Solar Heat Gain Coefficient (SHGC) on windows from 0.61 to 0.4 . For simplicity we assume that builders meet the new code standard by making the same change as that made to the baseline home. ${ }^{13}$ In practice, reducing the SHGC on residential windows requires purchasing windows with a low-emissivity, or "low-E," coating. Windows with a low-E coating typically cost between 10 and 15 percent more than regular windows (US DOE 2009b). Following the assumptions of Fairey and Sonne (2007), we assume that a standard Florida home has 400 square feet of windows, which is equivalent to approximately 27 doublehung $60 \times 30$-inch windows. Assuming a standard window costs $\$ 250$, supplying a house with low-E windows would add between $\$ 675$ and $\$ 1,012$ to overall construction costs. ${ }^{14}$

To compare against the higher construction costs are the benefits of lower utility bills for both electricity and natural gas. Referring back to Table 3, our estimates of the monthly energy savings are approximately $48 \mathrm{kWh}$ and 1.5 therms for electricity and natural gas, respectively. This implies an average annual savings of $576 \mathrm{kWh}$ and 18 therms. Based on GRU's block-rate pricing in 2009 and the distribution of monthly consumption levels observed in the data, the average marginal price that Gainesville Regional Utilities (GRU) currently charges consumers is $14.6 \$ / \mathrm{kWh}$, which consists of an $8.6 \mathbb{\$}$ average energy charge plus a $6 \mathbb{\$}$ fuel adjustment charge. These numbers imply that the average household built under the stricter code regime saves $\$ 84.10$ per year on its electricity bill. The marginal price of an additional therm of gas is $\$ 1.22$, consisting of a $48.3 \$$ energy charge, a $3.7 \$$ plant cost recovery fee, and a $70 \$$ purchased cost ad-

\footnotetext{
${ }^{13}$ This approach is the most tractable way to conduct the cost-benefit analysis, but it may lead to an overestimate of the compliance costs, as builders are able to exploit the flexibility of the code to comply with the change at a lower cost. Additionally, if builders tended to over-comply with the initial energy code and only a subset of builders had to take on additional costs to meet the new code, our approach would provide an overestimate of the compliance costs.

${ }^{14}$ As a point of comparison, the least expensive double-hung window on the website of the popular window-maker Anderson Corporation is priced at $\$ 271$.
} 
justment charge. Hence the combined estimated savings on electricity and natural-gas utility bills is approximately $\$ 106$ per year. It follows that even under the very best-case scenario-a 10 percent premium for low-E windows and a zero discount rate-the private payback period is roughly 6.4 years.

From a social perspective there are also benefits associated with a reduction in airpollution emissions. We estimate these benefits using a standard benefits-transfer approach for four categories of emissions: carbon dioxide $\left(\mathrm{CO}_{2}\right)$, sulfur dioxide $\left(\mathrm{SO}_{2}\right)$, nitrous oxide $\left(\mathrm{NO}_{\mathrm{x}}\right)$, and particulates (PM2.5). With respect to electricity, we calculate emission rates for $\mathrm{CO}_{2}, \mathrm{SO}_{2}$, and $\mathrm{NO}_{\mathrm{x}}$ for GRU using the US Environmental Protection Agencies (US EPA) eGRIDweb software. ${ }^{15}$ Because eGRIDweb does not provide emission rates for PM2.5, we obtain the estimate from Conners et al. (2005), which is a 2002 estimate that applies to Florida more generally. ${ }^{16}$ With these emission rates in hand, we calculate the change in emissions using our estimates in Table 3 for the reduction in electricity demand. We multiply the estimate of $48 \mathrm{kWh} / \mathrm{month}$ by 12 and the emission rate for each pollutant to estimate the annual change in emissions. Finally, we use marginal damage estimates for each of the pollutants to monetize the benefits of avoided damages. For $\mathrm{SO}_{2}, \mathrm{NO}_{\mathrm{x}}$, and $\mathrm{PM} 2.5$ emissions, we use high and low estimates specifically for Alachua County, Florida based on Muller and Mendelsohn's (2007) Air Pollution Emission Experiments and Policy (APEEP) analysis model. ${ }^{17}$ For $\mathrm{CO}_{2}$ emissions, we use low and high estimates of the social cost of carbon from Stern (2007) and Nordhaus (2008), respectively. The results for avoided damages from the reduction in electricity consumption, which range between approximately \$13 and \$74 per residence per year, are reported in the first two columns of Table 5.

\footnotetext{
${ }^{15}$ The software is available online at http://cfpub.epa.gov/egridweb/. Rates are based on the location (operator)based level of data aggregation for the most recent year of 2005 configured for industry structure through 2007.

${ }^{16}$ The Conner's et al. (2005) estimate is calculated by matching plant-level data on emission totals from US EPA's National Emissions Inventory (NEI) database to plant-level data on heat rates from eGrid. The authors then use this relationship to estimate the average emissions rate for PM2.5 for the entire Florida Reliability Coordinating Council (FRCC) Region.

${ }^{17}$ Because $\mathrm{SO}_{2}$ is regulated under a national cap, one might argue that the emission reductions in Gainesville will be offset by an increase in emissions elsewhere, and the appropriate measure of the benefits is the permit price, which represents the avoided marginal abatement costs. Here, however, the scope of our analysis is Gainesville, and we consider the avoided damages to be the benefits of emission reductions in the region.
} 
With respect to natural gas, our estimates in Table 3 for the reduction in consumption due to the energy-code change are very close to 1.5 therms per month, or 18 therms per year. To monetize the avoided damages for $\mathrm{SO}_{2}, \mathrm{NO}_{x}$, and PM2.5 emissions, we rely on recent estimates by region for the marginal damages of residential natural gas use for heat (NRC 2009). Within the south region of the United States, we use the $25^{\text {th }}$ and $75^{\text {th }}$ percentile estimates of the marginal damages for low and high cases, respectively. For $\mathrm{CO}_{2}$ emissions, we use NRC's (2009) estimate that burning one therm of natural gas generates 0.006 tons of $\mathrm{CO}_{2}$ combined with the low and high marginal damages described above. The results for avoided damages from the reduction in natural-gas consumption are reported in the in the middle columns of Table 5, and considering all four pollutants, the low and high estimates are approximately \$1 and \$10 per residence per year.

The last two columns of Table 5 report the combined avoided social damages for the reductions in both electricity and natural-gas consumption. While the overall estimates range between $\$ 14$ and $\$ 85$ per residence per year, reductions $\mathrm{CO}_{2}$ and $\mathrm{SO}_{2}$ account for the vast majority of benefits. Under the best-case scenario described above, along with the high estimates for avoided emission damages, the social payback period reduces to about 3.5 years. Nevertheless, one might argue that the benefits associated with lower $\mathrm{CO}_{2}$ emissions should not be considered in such cost-benefit calculations, as they are likely to occur for the most part outside the policy jurisdiction. Adjusting the payback period to exclude the $\mathrm{CO}_{2}$ benefits, we find that the best possible social payback period is 5.3 years.

\section{Discussion}

We are not aware of any existing study that uses residential billing data to evaluate the effect of increasing energy-code stringency on both electricity and natural-gas consumption. Perhaps the reason is that such studies face significant challenges. Among them is the need to find an appropriate set of “control” residences against which to compare "treatment” residences. One option, the standard difference-in-differences approach, is to use residences from a neighboring area that were not subject to the same energy-code change and estimate how the "before" and "after" en- 
ergy consumption differs between the two groups. The general concern with this approach, however, is that time trends in important observable and unobservable variables may differ between the two groups for reasons unrelated to the treatment, leaving models susceptible to bias. Another concern, more specific to energy codes, is that nearby treatment and control areas may not be entirely independent. For example, Horowitz (2007) analyzes the effect of state commitments to energy-efficiency programs on residential electricity consumption and finds evidence that spillovers from the programs are rapid and ubiquitous. Hence energy codes that change construction patterns in one area are likely to produce spillover effects on construction patterns in other, nearby areas.

The present paper estimates the effect of an energy-code change based on comparisons between residences in the same area constructed within three years before and three years after the code change, comprising the control and treatment groups, respectively. Using only monthly utility bills for the years after the code change, we employ two empirical strategies for both electricity and natural gas: comparisons of mean energy consumption, and differences in the responsiveness of energy consumption to variability in weather. The first approach produces our main results, which are that the energy-code change appears to have caused a 4-percent decrease in annual electricity consumption and a 6-percent decrease in annual natural-gas consumption. Moreover, differences in the savings by month are consistent with reduced consumption of electricity for air-conditioning and reduced consumption of natural gas for heating. The key identification assumptions, however, are that we appropriately control for the observable characteristics of each residence and that no unobservable characteristics differ between the pre- and post-codechange residences in ways that significantly affect energy consumption.

The primary advantage of our second empirical strategy is that we are able to control for unobservable, time-invariant heterogeneity among residences and still test for differences between those constructed pre- and post-code-change. Specifically, the fixed-effects models account for average differences in consumption among residences and test for differences in the response to weather variability, the main driver of fluctuations in energy demand. One interpretation of these models is as a robustness check against the other estimates of monthly differences 
explained by energy demand due to heating and cooling. If the energy-code change increases efficiency, then consistency between approaches would imply that more cooling degree days and heating degree days should be associated with less of an increase in electricity and natural-gas consumption, respectively, for the post-code-change residences. This is, in fact, precisely what we find.

Are there any alternative explanations for our empirical findings? One possibility is that a shift from natural-gas to electric heating, caused for reasons independent of the code change, is driving some of the results. This could explain, for example, the lower natural-gas consumption, especially during cold months, of the post-code-change residences, and the downward pattern in the effective year built dummies presented in Figure 4. Although this explanation is not consistent with anecdotal evidence about new construction in Florida, it would be ideal to control for this possibility with data on the type of heating of residences within our sample. Unfortunately these data are not available. However, even if there were some shifting from natural gas heating to electric heating, our primary results - that the code change is associated with reduced overall energy consumption—would be unchanged because we estimate annual energy savings for both electricity and natural gas.

How do our results compare to those of an engineering simulation model? According to EnergyGauge (2002), the energy-code change in Florida's northern climate region is predicted to cause a 4-percent increase in energy efficiency standards for space heating, space cooling, and water heating. But because these sources of energy demand account for only half of the energy demand for a typical Florida residence (Cushman 2008), the change in code stringency translates into a 2-percent increase in overall energy efficiency. This estimate is not statistically different than our empirical findings of a 4-percent savings for electricity and a 6-percent savings for natural gas.

Because of the difference between our point estimate and the engineering predictions, however, we now discuss a few reasons why the empirically estimated effects might plausibly be larger than the simulated predictions. First, energy-code changes are likely to generate spillover effects on construction patterns across regions, as discussed above. While our control and treat- 
ment groups are from the same area located within Florida’s northern climate region, more substantial changes occurred at the same time in the state's central and southern climate regions. It is possible that changes in the other regions caused a general shift in residential construction practices that resulted in more over-compliance with the energy code in the northern climate region. Second, there appears to have been confusion over what exactly the change in Florida's building code meant for builders. Several sources suggest that builders interpreted changes to the code as prescriptive requirements rather than components that could be traded off in the overall performance-based metric. ${ }^{18}$ This would, in practice, result in over-compliance with the energy code. Finally, new standards of the National Appliance Energy Conservation Act (NAECA) took effect in July 2001 and increased the efficiency standard for refrigerators. Fairey and Sonne (2001) predict that these new standards decrease electricity demand of a typical Florida residence by $12.5 \mathrm{kWh} / \mathrm{month}$. Applying this adjustment to our estimates would imply a decrease in electricity consumption of 3 percent, which is closer to the simulated prediction of the engineering simulation.

\section{Conclusion}

In response to the 1973 oil embargo, many U.S. states began passing building energy codes in order to promote energy efficiency. While the vast majority of states have energy codes in place, policymakers are now attempting to legislate energy codes at the federal level to help address heightened concern about energy and climate change. Despite widespread implementation of energy codes and calls for greater stringency in the future, surprisingly little is known about whether energy codes are an effective way to reduce energy consumption. Engineering simulations provide most of the evidence, but simulated predictions, even if based on sound models, do not account for enforcement, compliance, and behavioral responses. Hence there is an important

\footnotetext{
${ }^{18}$ For example, The National Fenestration Ratings Council published an article in its widely-read magazine NRFC Update in January that reported that the "Florida prescriptive requirements will require SHGC of 0.40 for all windows in the state effective January 2002." Additionally, a brochure entitled "The Florida Building Code and the Florida Home Builder" that contained a number of errors regarding the code change was distributed to attendees of the Southeastern Builders Conference held in Orlando in July 2001. The errors were later explained on the EnergyGauge (2002) website, but they demonstrate considerable confusion about energy code requirements that could result in over-compliance.
} 
and timely need for empirical research that uses field data to more fully evaluate the effects of energy codes on energy consumption.

The primary contribution of this paper is the evaluation of Florida's residential energycode change based on actual billing data for both electricity and natural gas. Using residences in the city of Gainesville, we find that the code is associated with a 4-percent decrease in electricity consumption and a 6 percent decrease in natural-gas consumption. Moreover, the pattern of savings is consistent with reduced consumption of electricity for air-conditioning and reduced consumption of natural gas for heating. Though direct comparison with engineering simulations is challenging, our estimates are reasonably close to those used by the state of Florida and thereby further general confidence in the reliability of simulated predictions. We also estimate economic costs and benefits of the energy-code change. We estimate that the private payback period for the average residence is 6.4 years. The social payback period, which accounts for the avoided costs of air-pollution emissions, ranges between 3.5 and 5.3 years, depending on whether avoided damages from carbon dioxide are included.

Given the policy relevance of understanding the current and potential impact of energy codes, it is worthwhile to conclude with comments about the generalizability of our results. The obvious limitation of the evaluation is that it applies to a particular policy in a particular location. Our selection of Gainesville and therefore Florida's energy code is based entirely on data availability that coincides with an energy-code change. Nevertheless, Gainesville, Florida might be considered an opportune place to study the impact of energy codes for several reasons. First, if trying to gauge the potential of energy codes, Florida is a good candidate state to study because it is known to have generally strict enforcement of building codes, due to the risks of major hurricane events. Second, 22 percent of all U.S. residences are in the same national climate region as Gainesville (EIA 2009), meaning that energy-code effects in Gainesville might be somewhat representative of how energy codes affect more general regions of the county, including all states that border the Gulf of Mexico, as well as parts of Georgia, South Carolina, Arkansas, Oklahoma, southern California and western Arizona. As for more northern climates, where demands for heating and cooling are substantially different, along with the mix of energy sources, we 
leave to future research the question of how energy codes affect actual energy consumption. But the methodology outlined in this paper should serve as a useful and replicable template for how studies can be carried out in other areas. 


\section{References}

Alachua County (2009). County website, section on history of building codes in Florida. Accessed on July 27, 2009 at http://growth-management.alachua.fl.us/codeenforce/buildcode.php.

Aroonruengsawat, A., M. Auffhammer, and A. Sanstad (2009). The impact of state level building codes on residential electricity consumption, Working paper, UC Berkeley.

Bashford, H. H., K. D. Walsh, and A. Sawhney (2005). Production system loading-cycle time relationship in residential construction. Journal of Construction Engineering and Management. 131 (1), 15-22.

Burk, J. (2008). A study of superintendent training and its effects on home building cycle time. MS Thesis, Brigham Young University. http://contentdm.lib.byu.edu/ETD/image/etd2435.pdf

Connors, S., K. Martin, M. Adams, E. Kern, and B. Asiamah-Adjei (2005). Emissions reductions from solar photovoltaic (PV) systems. MIT Laboratory for Energy and the Environment (LFEE), Report No.: 2004-003 RP.

Costa, D. L. and M. E. Kahn (2010). “Why Has California’s Residential Electricity Consumption Been So Flat Since the 1980s? A Microeconometric Approach,” NBER Working Paper 15978.

Cushman, T. (2008). Florida sets tough energy code targets. Builder: The Information Source for the Home Building Industry. Posted July 23, 2008. http://www.builderonline.com/codesand-standards/florida-sets-tough-new-energy-targets.aspx

Energy Information Administration (2006). South Atlantic Household Electricity End Uses: A/C, Heating, Appliances. Accessed on November 25, 2009 at the following web address http://www.eia.doe.gov/emeu/reps/enduse/er01_so-atl.html.

EnergyGauge (2002). Florida's new 2001 energy code. Accessed on July 27, 2009 at http://www.energygauge.com/FlaRes/new_code.htm.

Fairey, P. and J. Sonne (2007). Effectiveness of Florida's residential energy code: 1979-2007. Contract Report conducted by Florida Solar Energy Center, submitted to Codes and Standards Office, Florida Department of Community Affairs.

Greening, L. A., D. L. Greene, and C. Difiglio (2000). Energy efficiency and consumption-the rebound effect—a survey. Energy Policy. 28 (6-7), 389-401.

Horowitz, M. J. (2007). Changes in electricity demand in the United States from the 1970s to 2003. The Energy Journal. 28(3): 93-119.

Horowitz, M. J. and H. Haeri (1990). "Economic Efficiency $v$ Energy Efficiency: Do Model Conservation Standards Make Good Sense?” Energy Economics. 12 (2), 122-131. 
Jaffe, A. B. and R. N. Stavins (1995). Dynamic incentives of environmental-regulations: The effects of alternative policy instruments on technology diffusion. Journal of Environmental Economics and Management. 29 (3), S43-S63.

Joskow, P. L. (1994). "More from the Guru of Energy Efficiency: 'There Must Be A Pony!'” The Electricity Journal, 7 (4), 50-61.

Joskow, P. L. and D. B. Marron (1993). "What Does a Negawatt Really Cost? Further Thoughts and Evidence," The Electricity Journal, 6 (6), 14-26.

Lucas, R. (2007). Analysis of energy saving impacts of new residential energy codes for the gulf coast. Prepared for U.S. Department of Energy under Contract DE-AC05-76RL01830 by the Pacific Northwest National Laboratory.

Lovins, A. B. (1994). "Apples, Oranges, and Horned Toads: Is the Joskow \& Marron Critique of Electric Efficiency Costs Valid?” The Electricity Journal, 7 (4), 29-49.

Metcalf, G. E. and K. A. Hassett (1999). Measuring the energy savings from home improvement investments: Evidence from monthly billing data. The Review of Economics and Statistics, 81(3): 516-528.

Muller, N. Z. and R. Mendelsohn (2007). Measuring the damages of air Pollution in the United States. Journal of Environmental Economics and Management. 54(1): 1-14.

National Research Council (2009). Hidden Costs of Energy: Unpriced Consequences of Energy Production and Use. Washington, D.C.: National Academies Press.

Nordhaus, W. (2008). A Question of Balance: Weighing The Options on Global Warming Policies. New Haven: Yale University Press.

Stern, N. (2007). The Economics of Climate Change: The Stern Review. Cambridge: Cambridge University Press.

US Department of Energy (2009a). Status of state energy codes. Accessed on Nov. 23, 2009 at http://www.energycodes.gov/implement/state_codes/index.stm.

US Department of Energy (2009b). Low-emissivity window glazing or glass. Accessed on Nov. 23, 2009 at http://energysavers.gov/your_home/windows_doors_skylights/index.cfm/mytopic=13430

US Green Building Council (2009). Green building research. Accessed on Nov. 23, 2009 at http://www.usgbc.org/DisplayPage.aspx?CMSPageID=1718. 


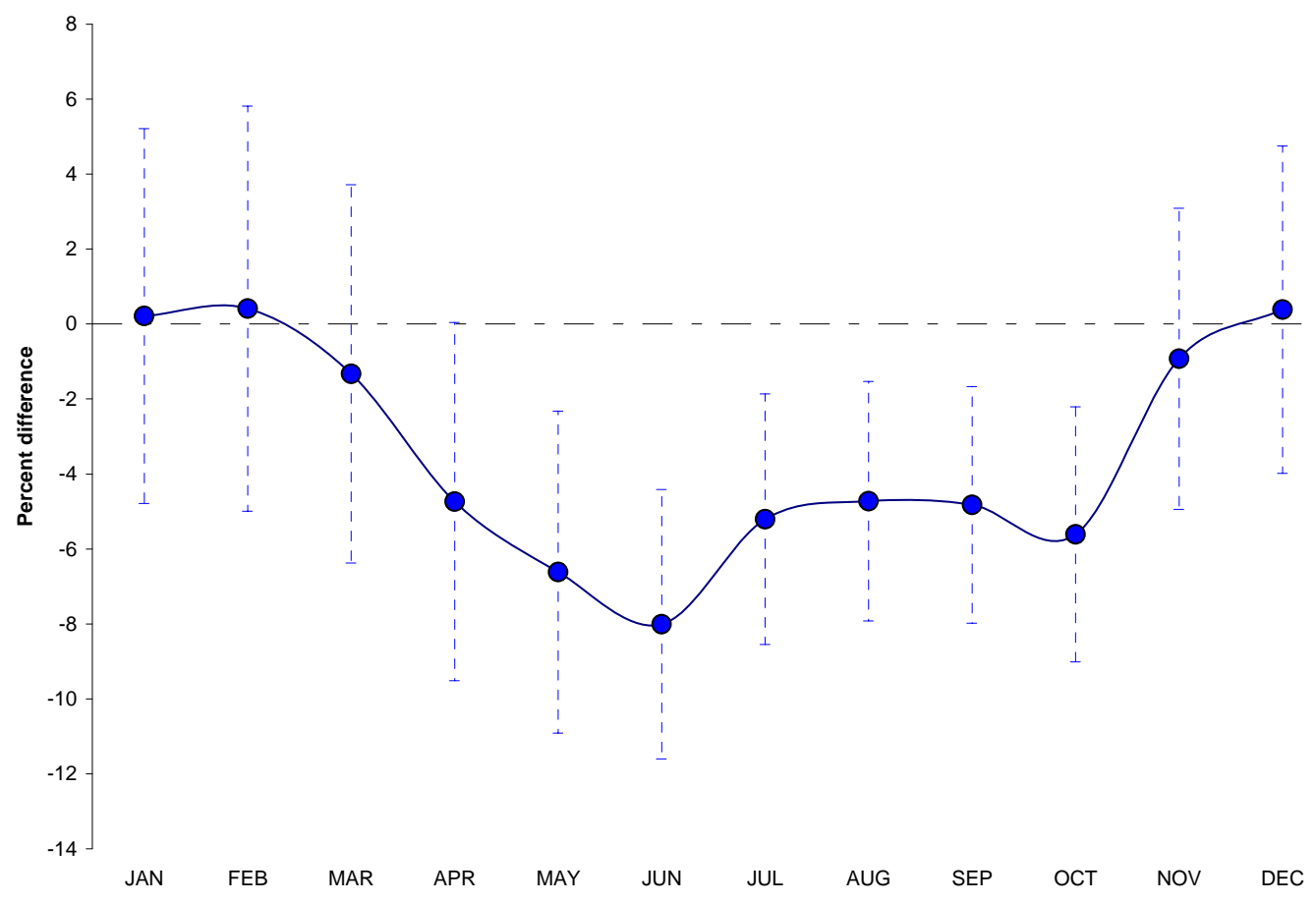

Figure 1: By month percentage difference in electricity consumption between residences constructed before and after the energy-code change

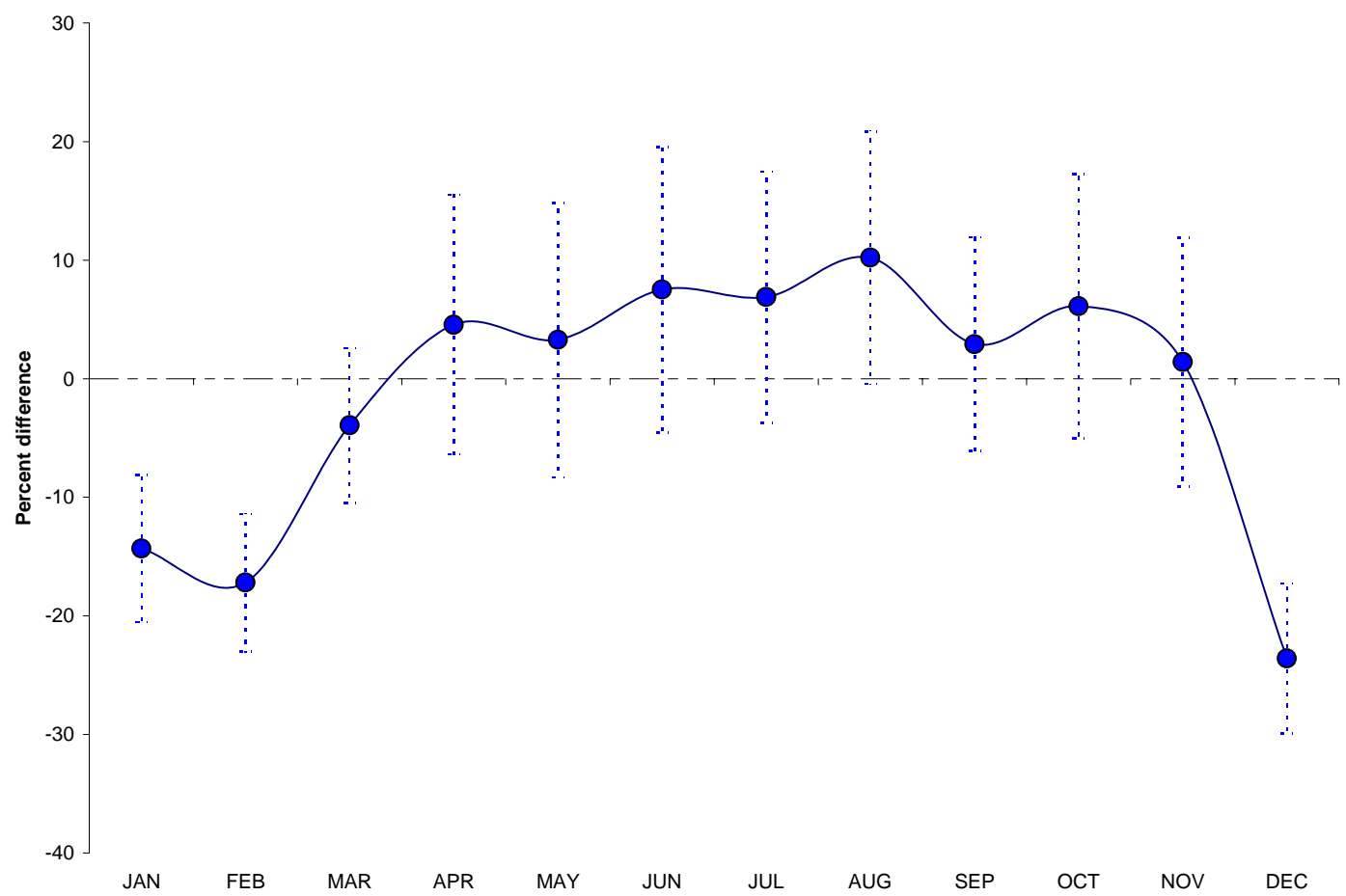

Figure 2: By month percentage difference in natural gas consumption between residences constructed before and after the energy-code change 


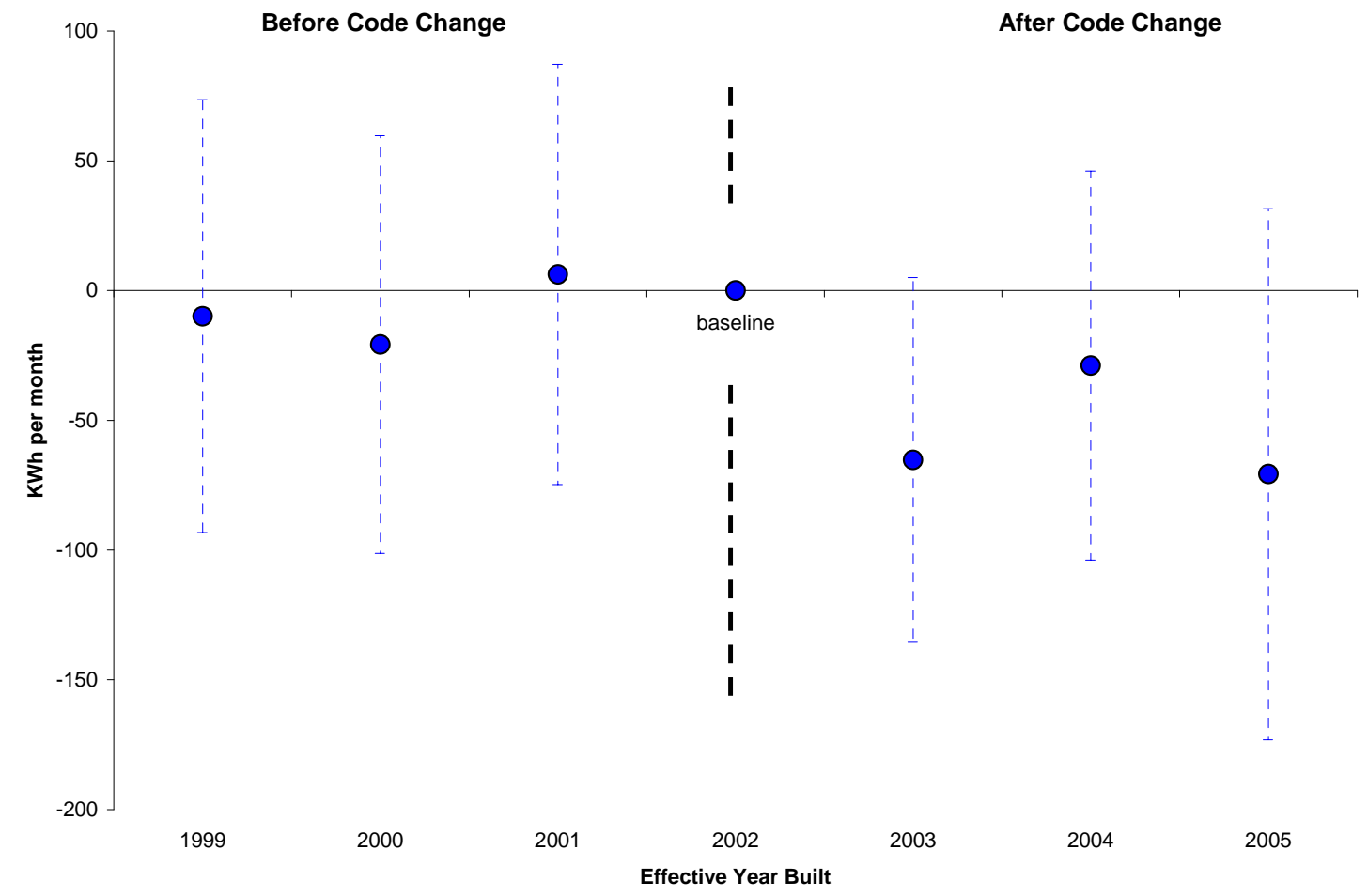

Figure 3: Differences is mean electricity consumption by effective year built based on specification (3)

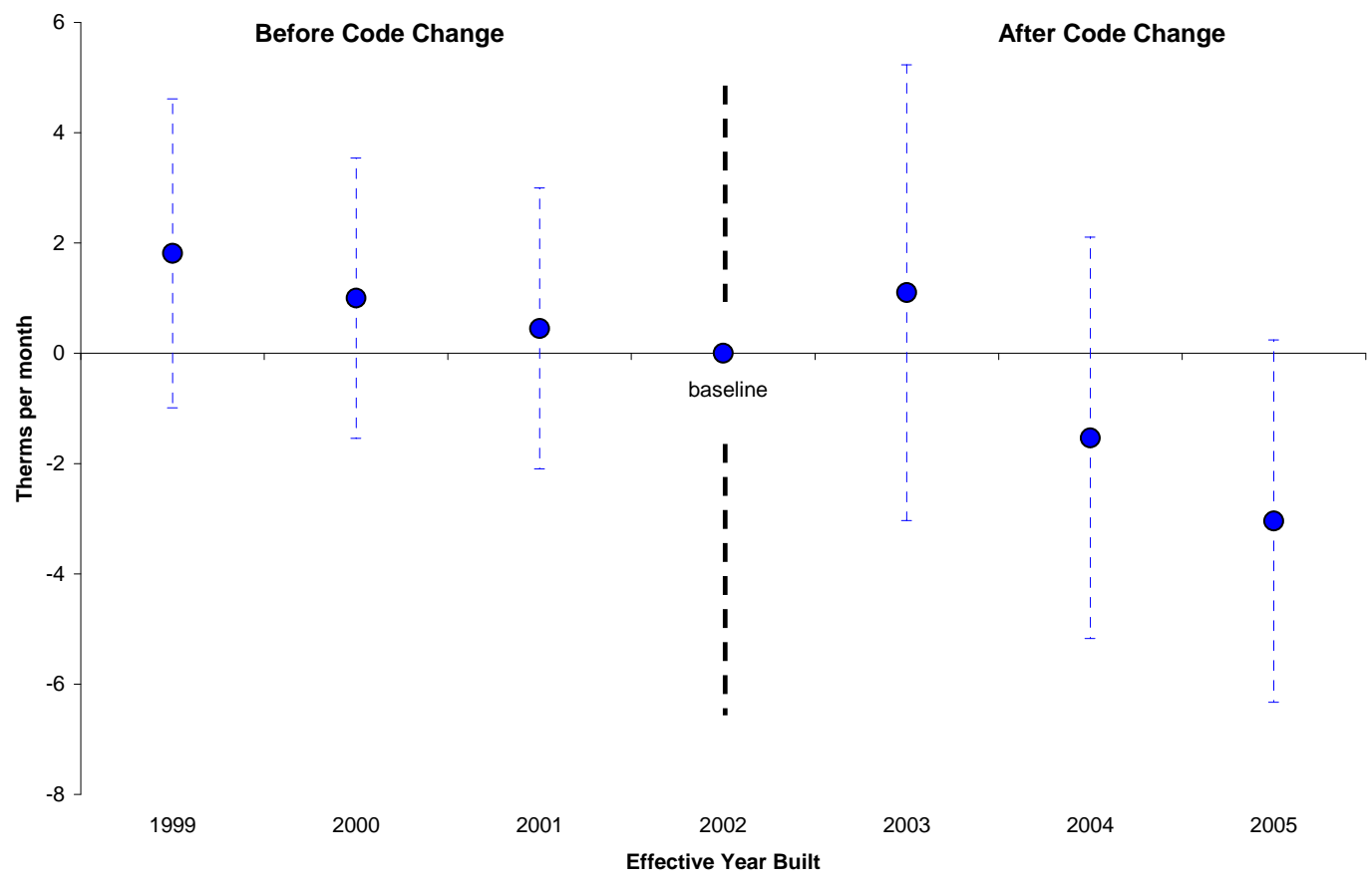

Figure 4: Differences is mean natural consumption by effective year built based on specification (3) 


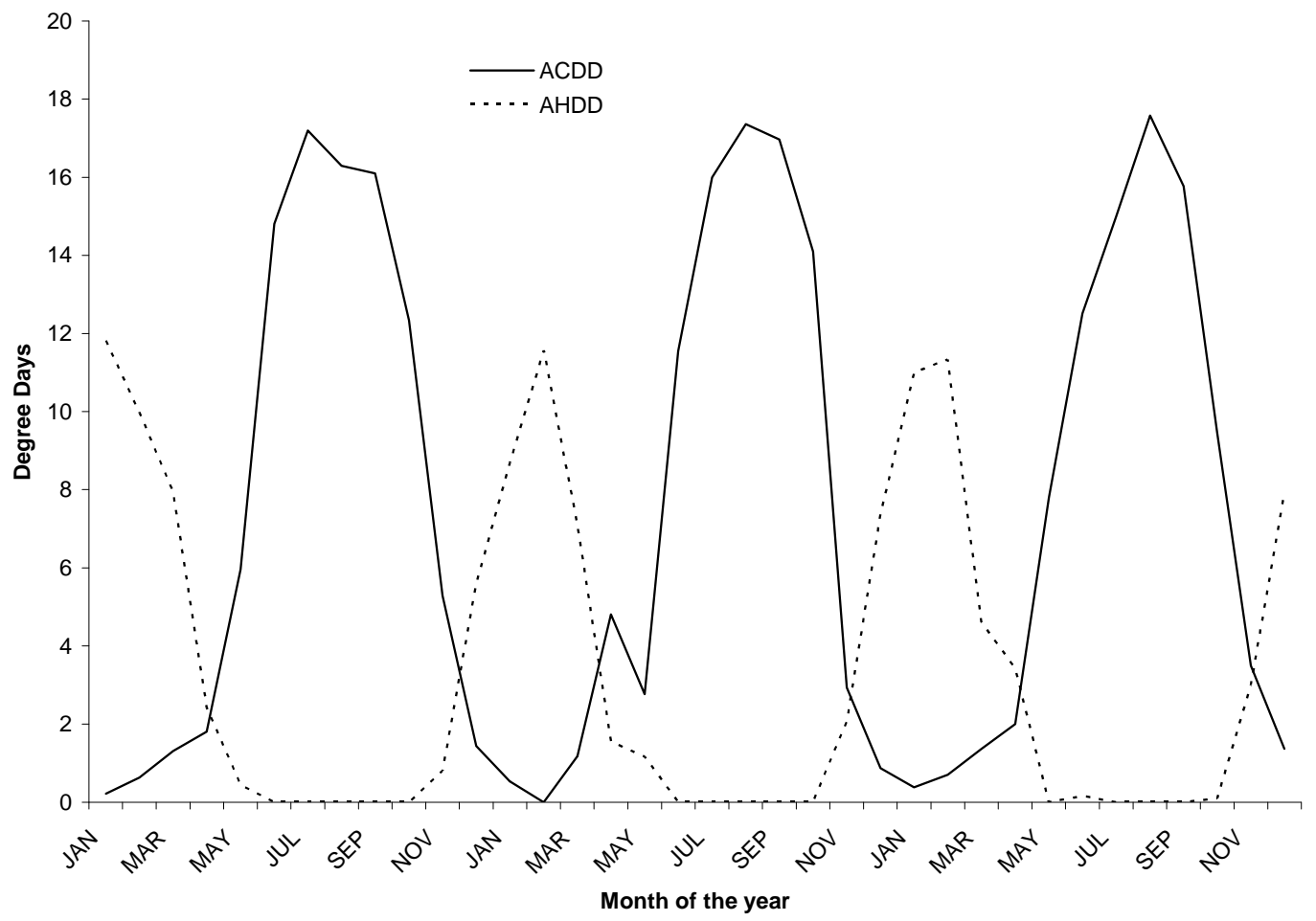

Figure 5: Variability of weather variables by month-year, 2004-2006 
Table 1: Summary Statistics

\begin{tabular}{lrrrr}
\hline \hline Variable & Mean & St. Dev. & Min. & Max. \\
\hline Electricity (kWh) & 1146.352 & 736.230 & 1 & 9138 \\
Natural gas (therms) & 23.633 & 30.353 & 0 & 661 \\
Effective year built (EYB) & 2000.931 & 1.895 & 1999 & 2005 \\
Square feet & 2072.541 & 764.191 & 784 & 7465 \\
Bathrooms & 2.279 & 0.574 & 1 & 6 \\
Bedrooms & 3.359 & 0.621 & 2 & 5 \\
Stories & 1.126 & 0.335 & 1 & 3 \\
Central air-conditioning & 0.997 & 0.058 & 0 & 1 \\
Shingled roof & 0.993 & 0.085 & 0 & 1 \\
Billing year & 2005.130 & 0.807 & 2004 & 2006 \\
Billing month & 6.658 & 3.427 & 1 & 12 \\
Average cooling degree days (ACDD) & 7.648 & 6.588 & 0.000 & 17.581 \\
Average heating degree days (AHDD) & 3.208 & 4.055 & 0.000 & 11.813 \\
\hline \hline
\end{tabular}

Summary statistics are based on 64,471 observations.

Table 2: Energy consumption and residential characteristics of residences built before and after the code change

\begin{tabular}{lcccc}
\hline \hline \multicolumn{1}{c}{ Variable } & $\begin{array}{c}\text { Before code } \\
\text { change }\end{array}$ & $\begin{array}{c}\text { After code } \\
\text { change }\end{array}$ & Diff. & t-stat. \\
\hline Electricity $(\mathrm{kWh})$ & 1149.851 & 1104.998 & -44.853 & 1.793 \\
& 616.784 & 537.390 & & \\
Natural gas (therms) & 23.224 & 17.450 & -5.774 & 7.977 \\
Square feet & 16.436 & 17.554 & & \\
& 2084.917 & 1990.758 & -94.159 & 2.939 \\
Bathrooms & 785.889 & 694.664 & & \\
& 2.276 & 2.266 & -0.010 & 0.404 \\
Bedrooms & 0.577 & 0.537 & & \\
& 3.360 & 3.329 & -0.032 & 1.202 \\
Stories & 0.628 & 0.597 & & \\
& 1.132 & 1.104 & -0.029 & 1.138 \\
Central air-conditioning & 0.343 & 0.305 & & \\
& 0.998 & 0.993 & -0.006 & 2.163 \\
Shingled roof & 0.039 & 0.086 & & \\
& 0.995 & 0.990 & -0.004 & 2.043 \\
\hline \hline
\end{tabular}

The data include 1,293 residences built before the code change and 946 residences built after the code change. Standard deviations are reported in parentheses. 
Table 3: Pre- and post-code-change comparisons for electricity and natural-gas consumption

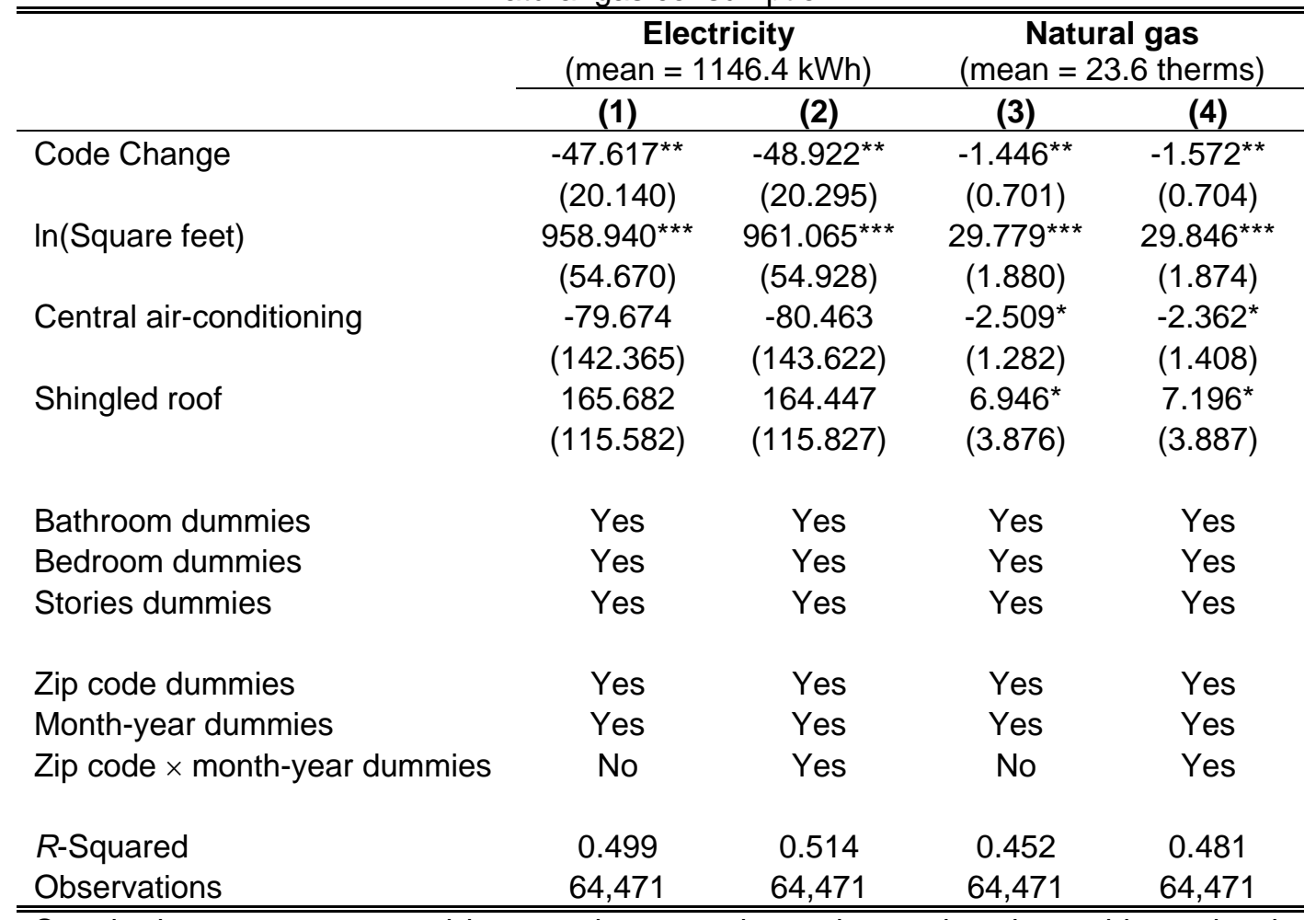

Standard errors are reported in parentheses and are clustered at the residence level. One, two, and three asterisks indicate significance at the $p<0.10, p<0.05$, and $p<$ 0.01 level, respectively. 
Table 4: Difference-in-differences estimates for electricity and natural-gas consumption due to weather variability

\begin{tabular}{lcccc}
\hline \hline Dependent Variable: & \multicolumn{2}{c}{ Electricity } & \multicolumn{2}{c}{ Natural Gas } \\
\cline { 2 - 5 } & $\mathbf{( 1 )}$ & $\mathbf{( 2 )}$ & $\mathbf{( 3 )}$ & $\mathbf{( 4 )}$ \\
\hline Code Change x ACDD & $-2.498^{\star \star}$ & $-3.500^{\star \star \star}$ & $-0.172^{\star \star \star}$ & $-0.161^{\star \star \star}$ \\
& $(1.187)$ & $(1.223)$ & $(0.051)$ & $(0.053)$ \\
Code Change x AHDD & $2.446^{\star \star}$ & $3.519^{\star \star}$ & $-1.372^{\star \star \star}$ & $-1.164^{\star \star \star}$ \\
& $(1.377)$ & $(1.379)$ & $(0.154)$ & $(0.155)$ \\
ACDD & $32.250^{\star \star \star}$ & -- & $-0.268^{\star \star \star}$ & -- \\
& $(0.961)$ & -- & $(0.044)$ & -- \\
AHDD & $6.362^{\star \star \star}$ & -- & $2.326^{\star \star}$ & -- \\
& $(1.287)$ & -- & $(0.111)$ & -- \\
Month dummies & & & & Yes \\
Year dummies & Yes & No & Yes & No \\
Month-year dummies & Yes & No & No & Yes \\
Residence fixed-effects & No & Yes & Yes & Yes \\
R-Squared & Yes & Yes & & \\
Observations & & & 0.456 & 0.462 \\
\hline \hline
\end{tabular}

Standard errors are reported in parentheses and are clustered at the residence level. One, two, and three asterisks indicate significance at the $p<0.10, p<0.05$, and $p<0.01$ level, respectively.

Table 5: Social benefits of avoided emissions from reduced electricity and natural-gas consumption

\begin{tabular}{lcccccc}
\hline \hline & \multicolumn{2}{c}{ Electricity } & \multicolumn{2}{c}{ Natural gas } & \multicolumn{2}{c}{ Combined } \\
\cline { 2 - 7 } & Low \$ & High \$ & Low \$ & High \$ & Low \$ & High \$ \\
\hline Carbon Dioxide $\left(\mathrm{CO}_{2}\right)$ & 4.37 & 53.12 & 0.83 & 10.12 & 5.21 & 63.24 \\
Sulfur Dioxide $\left(\mathrm{SO}_{2}\right)$ & 7.90 & 19.65 & 0.00 & 0.01 & 7.90 & 19.66 \\
Nitrous Oxide $\left(\mathrm{NO}_{\times}\right)$ & 0.75 & 1.17 & 0.09 & 0.23 & 0.84 & 1.40 \\
Particulates $(\mathrm{PM} 2.5)$ & 0.20 & 0.53 & 0.00 & 0.01 & 0.21 & 0.54 \\
Total & $\mathbf{1 3 . 2 3}$ & $\mathbf{7 4 . 4 7}$ & $\mathbf{0 . 9 2}$ & $\mathbf{1 0 . 3 7}$ & $\mathbf{1 4 . 1 5}$ & $\mathbf{8 4 . 8 4}$ \\
\hline \hline
\end{tabular}

Benefits are reported in $\$ 2009$ s. Methods of derivation and explanations of low and high scenarios are included in the main text. 